\title{
Effects of Light Radiation Absoption on the Resistance of Sweet Potato Starch-Based Bioplastics
}

\author{
Aristide Herlyn Wilfrid Nakavoua ${ }^{*}{ }^{\mathbb{D}}$, Emmanuelle Surya Ouenadio $^{2}$, \\ Pascale Ursula Nkoua-Ouassamo², Vincent Verney ${ }^{3}$ \\ ${ }^{1}$ Laboratory of Natural Substances Chemistry (IRSEN), Brazzaville, Congo \\ ${ }^{2}$ Laboratory for The Valorisation of Agri-Resources, Ecole Normale Superieure Politechnique (ENSP), Marien Ngouabi \\ University, Brazzaville, Congo \\ ${ }^{3}$ UMR 6296 Team Design of Polymers and Macromolecules Scientist Set Cézeaux, Institute of Chemistry of Clermont-Ferrand \\ (ICCF), Clermont-Ferrand, French \\ Email: ^a.nakavoua@lycee-saintexbrazza.org
}

How to cite this paper: Nakavoua, A.H.W., Ouenadio, E.S., Nkoua-Ouassamo, P.U. and Verney, V. (2022) Effects of Light Radiation Absoption on the Resistance of Sweet Potato Starch-Based Bioplastics. Journal of Materials Science and Chemical Engineering, 10, 44-52.

https://doi.org/10.4236/msce.2022.102004

Received: January 5, 2022

Accepted: February 25, 2022

Published: February 28, 2022

Copyright $\odot 2022$ by author(s) and Scientific Research Publishing Inc. This work is licensed under the Creative Commons Attribution International License (CC BY 4.0).

http://creativecommons.org/licenses/by/4.0/

\begin{abstract}
The strength of starch-based bioplastics is a challenge, we tried to overcome this limitation by using electromagnetic radiation in the visible range. Synthetically obtained retrograde bioplastics were subjected to radiation from an Edison-type incandescent lamp. A cross-linked network is obtained within the bioplastic matrix considerably attenuating the usual hygroscopicity of starch and increasing the ability to resist rupture. After this positive behavior, the bioplastics were colored in order to optimize the action of light radiation. The results show a stronger and more compact bioplastic. The green-colored bioplastics show the best performance in the optimization of the resistance.
\end{abstract}

\section{Keywords}

Bioplastics, Starch, Sweet Potato, Radiation and Light Stress

\section{Introduction}

Plastics offer a wide range of properties and applications and are today an important or even indispensable material for many industries [1]. The global demand for this group of materials is constantly increasing, but so are the requirements in terms of performance and quality.

The race towards bioplastics represents for countries with a high diversity of agro-resources a major challenge. The desire for sustainable development and greater protection of the climate is accentuated by the best use of their produc- 
tion of amylaceous products [2].

Our bio-plastics were obtained from sweet potato starch, a seasonal foodstuff but very much appreciated by the Congolese for its very pronounced sweet taste compared to tubers or other starchy roots [3]. This root, very rich in reducing sugar, gives a very little studied starch, which confers to this work a slight empirical character especially in its aspect of production of retrograded and colored bio plastics based on sweet potato.

However, it is necessary to underline that the results obtained during these various works edified us but also confirm that one of the outlets of the sweet potato spinneret can be the one explored by our centers of interests which inspired this work.

\section{Material and Methods}

\subsection{Plant Material}

Our study was carried out on all-planted sweet potatoes (ipomeabatata) with yellow skin sold on the total market place of Brazzaville (Congo). The potatoes were selected on the basis of visual quality; all damaged potatoes were discarded.

\subsection{Starch Extraction}

The starch used for bioplastic synthesis was extracted from sweet potato (ipomeabatata) pulp.

After receiving the material (sweet potato), it is cleaned and peeled before being grated. The grated pulp thus recovered is placed in a container in which drinking water is added, the whole is well mixed with a spoon. This mixture is then filtered through a sieve. The filtrate obtained is subjected to a decantation and 2 hours later the supernatant is removed with a pipette; the starch obtained is dried in the open air for two days [4].

The extraction yield of the starch obtained is described by the following formula:

$$
R(\%)=\frac{M_{0}-M_{1}}{M_{0}} \times 100
$$

$M_{0}=$ mass of peeled sweet potatoes;

$M_{1}=$ mass of harvested starch.

\subsection{Elaboration of Bioplastics}

To elaborate our plastic films we have:

Prepared in a pan, $300 \mathrm{~mL}$ of distilled water, $10 \mathrm{~mL}$ of glycerol and $15 \mathrm{~g}$ of starch;

> Mixed and brought to a boil until it became thick and translucent;

Added $2 \mathrm{~g}$ of food coloring and continued to heat for $10 \mathrm{~min}$ without stopping stirring with a wooden spatula [4];

Placed the glass plate on the bench and pour the still hot and liquid mixture; 
let it cool down in $1 \mathrm{~h}$ to let the bubbles escape then place it in the oven at $100^{\circ} \mathrm{C}$ for $24 \mathrm{~h}$.

\subsection{Sampling}

We have two types of samples: Type A; circular shaped bioplastic $3.5 \mathrm{~cm}$ in diameter. Type B; bioplastic in the shape of a rectangle with dimensions of $8.5 \mathrm{~cm}$ in length and $2 \mathrm{~cm}$ in width.

\subsection{Resistance According to the Mass}

This characteristic allows us to judge the mechanical strength of our films. We cut the plastic film of dimension $8.5 \mathrm{~cm}$ of length and $2 \mathrm{~cm}$ of width. Then cut paper of the same dimensions that we fixed to the film sample with glue, leaving 1.5 centimeters of plastic overflowing upwards to be hung with a clamp (Figure 1). Two types of attraction experiments were performed.

Experiment 1: A successive pull with 5 minutes of pause. 10 minutes after the bioplastic has been positioned on the device. $5 \mathrm{~g}$ are added every 5 minutes until the break.

Experiment 2: A direct traction: once the breaking mass is known (experiment 1), the bioplastic is hooked directly and the time is measured.

To the centimeters of paper overflowing downwards were hung different masses. Every 10 minutes a new mass was hung (higher than the previous one) after measuring the length of the plastic film.

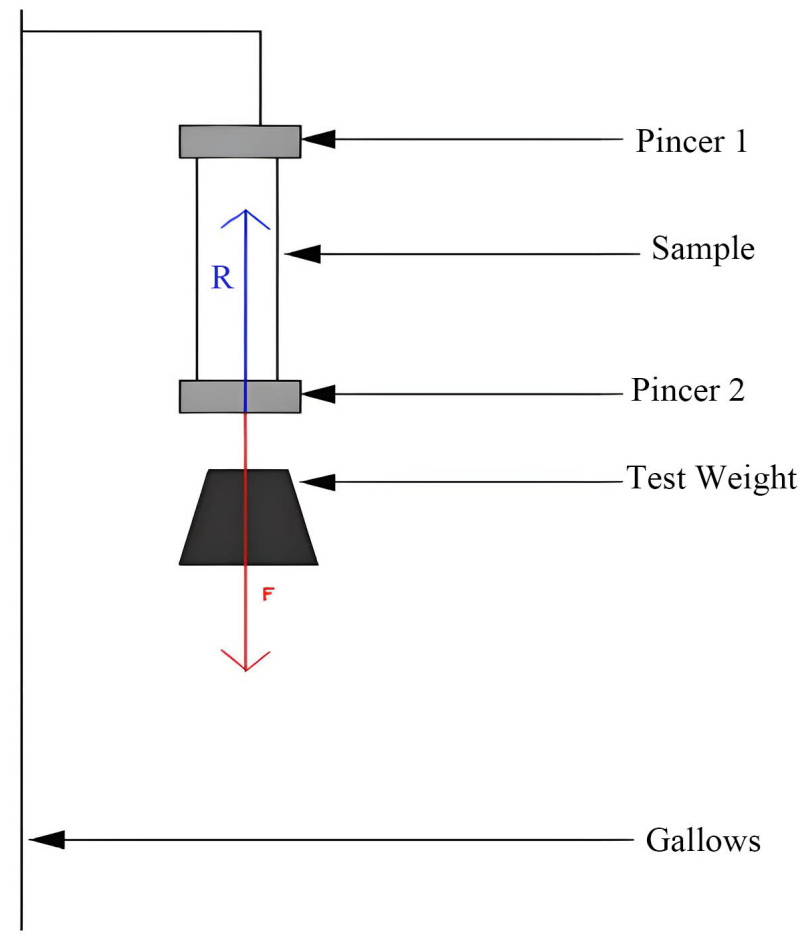

Figure 1. Device which allowed to obtain the breaking tension, Thesis jbilou Fouzia 2011 [5]. 


\subsection{Behavior in Front of the Radiations}

The aging chamber (Figure 2) is a device designed specifically to model solar aging on our bioplastic samples. It is a wooden box of $15.6 \mathrm{~m}^{3}$ of volume whose interior is covered with a black plastic sheet. On the upper side is placed an incandescent lamp at $15 \mathrm{~cm}$ from the sample connected to an electric cable connected to an electric voltage regulator so that the power supply of the lamp is indicated throughout the experiment.

The type A samples are placed in the chamber on the piece of NACO glass serving as a rack with in the chamber located $15 \mathrm{~cm}$ from the Edison lamp. The internal temperature $t_{i}$ is noted immediately after closing the chamber. The circuit is closed by means of a switch placed up stream of the lamp, which is left on for 20 minutes. The internal temperature $t_{f}$ is read again before opening the chamber in order to measure the diameter of the sample with a precision ruler (metal blade graduated in half millimeters). The process is repeated until the radiation exposure is 200 minutes. After 10 measurements, the temperatures are averaged to determine the $\lambda \max$ and deduce the wavelength range reached using Wien's law.

\section{Results and Discussion}

\subsection{Extraction of Starch}

Starch is very easy to extract. The yield obtained is: $R=9.5 \%$, which proves that sweet potato is a starch rich root. It should be remembered that sweet potato is most often used as a complementary food [6]. This yield is rather low compared to that reported by Tshizembe et al. [7] on cassava tubers.

\subsection{Film Processing}

Like most of the products resulting from a retrogradation of starch in the presence of a plasticizer glycerol, the films obtained have a rubbery aspect. The resistance to touch seemed to us suitable [8]. The thickness chosen by flattening two glasses reflects that changes have occurred within the matrix of the macromolecule.

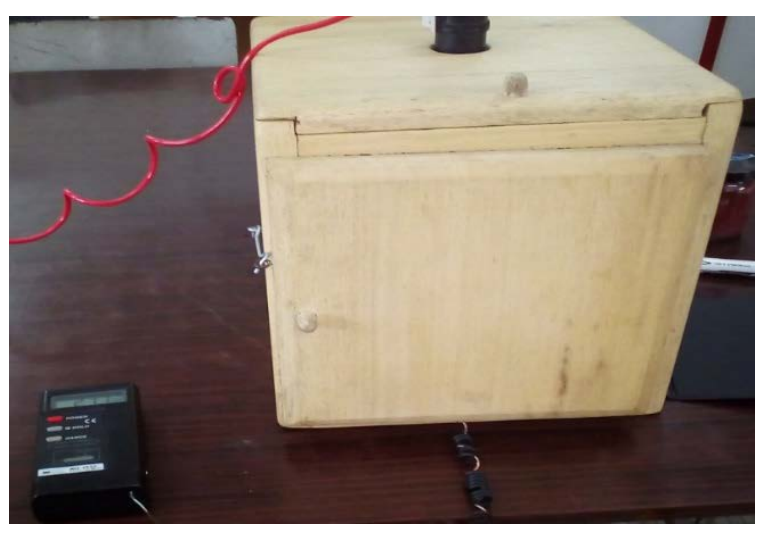

Figure 2. Laboratory aging chamber, LVAR, ENSP, July 2020. 
The incorporation of the different dyes brings a well distinguished shine on the texture of our subjects, although the texture did not undergo any palpable change.

Glycerol was used as a plasticizer [9]. It does not interact chemically with the matrix in which it is dispersed. It simply increases the free volume between two polymer chains to decrease the interactions and thus promote the movement of one with respect to the other. The presence of this plasticizer allows to reduce the heating because the plasticizer has already introduced free volume between the chains. We thus pass from a rigid material to a plastic. The manufactured film is thus more resistant to tension and bending. In addition, the addition of glycerol makes the plastic film transparent, which is very useful for packaging purposes.

Heating serves to destructure the starch [10]. Once destructured, the starch mixed with glycerol can be shaped. A destructured starch is a starch that is no longer in its original grain form: the constituent polymers (amylose and amylopectin) are dispersed. Thus we have obtained a plastic film.

\subsection{Resistance to Rupture}

The breaking strength is an important characteristic for bioplastics used as packaging.

Indeed, packaging is characterized by, among other things, its ability to resist different stresses such as torsion occurring during load bearing [11].

It can be seen (Figure 3) that the bioplastic that has not been subjected to any light stress breaks after two strength levels; this corresponds to a mass of $50 \mathrm{~g}$. From this result, it can be stated that the crystal structure of the sweet potato starch bioplastic is quite fragile. With this mass, the rupture occurs after 3 minutes of traction (experiment 2). However, if the $50 \mathrm{~g}$ are reached after additions every 5 minutes (experiment 1), the breakage occurs after 35 minutes. However, the play of light stress improves considerably its resistance capacity. This results in a higher strength plateau than that of an unstressed bioplastic. The improved crystal lattice reaches a value at load equal to $70 \mathrm{~g}, 20 \mathrm{~g}$ more than the unstressed bioplastic. This expresses a structural improvement of $40 \%$. With a load of $70 \mathrm{~g}$, the rupture occurs after 5 minutes of tension (experiment 2) whereas experiment 1 for this type of bioplastic allows to record a time of 50 minutes to reach the rupture.

This result allows to attest that the bioplastic based on sweet potato starch having undergone a structural and textural modification by light stress can be used as packaging.

\subsection{Impact of Radiation}

The action of the light from the Edison lamp, combined with the temperature emitted by this lamp, produces a decrease in the radius of the bioplastic sample cut in a circle (type A). This result is consistent with the one already obtained during the analysis of the tensile strength of type B samples. Indeed, the decrease 
in radius observed is most certainly the result of the formation of cross-links that modify the bioplastic matrix [12].

The curves show two steps that correspond respectively to a dehydration and a structural reorganization of the bioplastic matrix. However, Figure 4 shows that this modification does not occur in the same way for the different bioplastics synthesized.

Indeed, the bioplastic dyed in black is the one which undergoes less the reduction of the radius. The first step occurs after a reduction of $0.15 \mathrm{~mm}$ after $3 \mathrm{mi}$ nutes. This result is in agreement with a number of physical principles which show that a black body absorbs heat. This absorbed heat is responsible for the dehydration that takes place within the bioplastic [13]. Thus the spaces freed by the water molecules probably facilitated the reorganization of the crystal lattice of the bioplastic, hence a longer plateau.

\section{breaking tension}

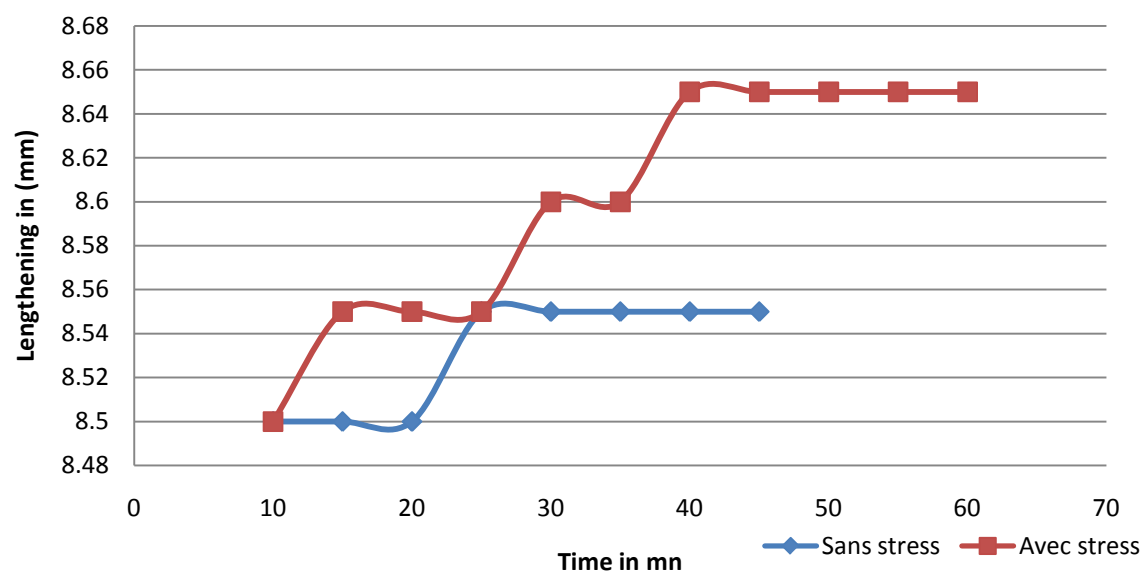

Figure 3. Behavior of bioplastics as a function of the breaking tension.

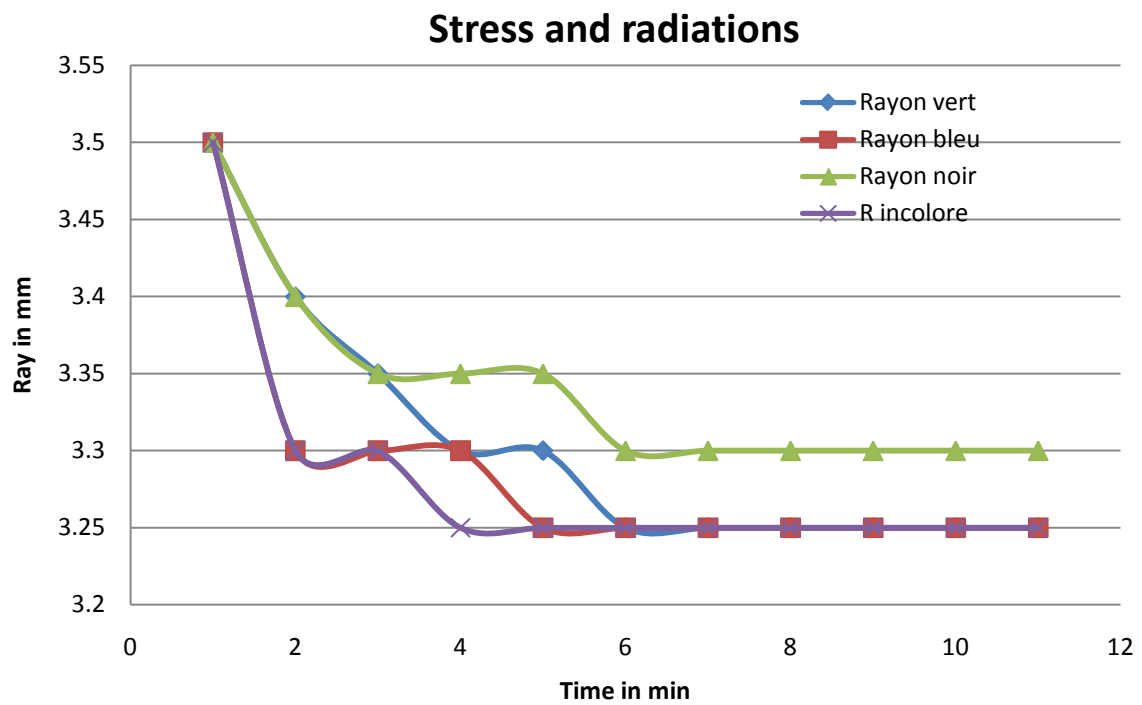

Figure 4. Behavior of bioplastics as a function of radiation received. 
Thus light is the cause of the improvement of the properties of the bioplastic, in particular the elasticity which is the property that a solid material has to find its original shape after having been deformed, i.e. that its dimensions change, but it takes again its initial shape when the solicitation stops. We can thus conclude that the absorption of the radiations emitted from the Edison lamp by the black bioplastic creates a rearrangement of the relative position of the atoms, or more generally of the elements constituting the material [14].

The application of Wien's law in this matter allowed us to note that the maximum wavelength absorbed by the bioplastic is $\lambda \max =7982.78 \mathrm{~nm}$ this being only an average obtained from the different temperatures collected during this analysis. This value is in the infrared range which corresponds to a low energy. The interior of the aging chamber reaches a temperature whose maximum wavelength equivalent by Wien's law is in the infrared range, which allows us to think that the modifications that occurred within the bioplastic matrix and that are observed here are due to absorptions in the infrared range, therefore at the level of the various bonds forming the bioplastic matrix, in particular the $\mathrm{O}-\mathrm{H}$ (hydroxyl) bonds but also the $\mathrm{C}-\mathrm{O}$ (carbon-oxygen) bonds.

The colorless bioplastic shows the fastest reduction with $0.2 \mathrm{~mm}$ with a very short first step. This result confirms the previous conclusions. Indeed, the bioplastic having a beige color at the beginning absorbs very little heat which does not support the dehydration thus does not release enough water molecules. Everything happens as if the water molecules accumulate the little heat absorbed by the bioplastic and undergo a rapid evaporation once the energy becomes sufficient, hence the short first stage. On the other hand, the bioplastic diffuses a good part of the radiations emitted by the Edison lamp which disadvantages the formation of the cross-links because the radiations responsible for this action do not reach the matrix of the bioplastic. This result shows that the shortening of the radius is due to the temperature that accompanies the brightness of the Edison lamp. While the formation of cross-links is the result of the absorption of light radiation. This bioplastic will have finally shortened of $0.25 \mathrm{~mm}$.

The analysis of the blue and green samples reveals a divergent behavior. Indeed, the blue sample has the same behavior as the colorless sample, a rapid shortening but however its first step is consistent with the black sample which suggests that it absorbs a lot of heat like the black sample. This result is in agreement with the spectrum of the Edison lamp rich in high wavelength radiation, but also with the value of $\lambda \max =7897.80 \mathrm{~nm}$ obtained by Wien's law.

The green sample undergoes a slow kinetics of shortening and displays a behavior identical to that of the colorless sample with a first short plateau as that of the colorless sample, however this intervenes after 4 minutes. This result is in agreement with the spectrum of the Edison lamp rich in red radiations which confirms our previous conclusions. Indeed, an object of green color absorbs in a maximum way the red radiations in particular magenta [15] which explains an increasing number of cross-linkings formed in the bioplastic of this color. 
In general, these results allow us to say that in the case of an industrial use, the bioplastics based on sweet potatoes would give better performances by being colored in particular in green because this sample gives an intermediate behavior between the colorless and the black.

\section{Conclusions}

The main objective of our work was to elaborate bio films based on sweet potato starch; respectful of the environment and have good mechanical and physical properties. For that, we proceeded to the extraction of the sweet potato starch whose yield amounted to $9.5 \%$. We then synthesized the bio plastic from this starch.

The bio plastics obtained had a rubbery and not very translucent aspect. After measuring some characteristics, we found that the bioplastics displayed a very hydrophilic character and poor mechanical properties that affect their natural degradation.

In order to improve the properties of the obtained biosheets, we studied their behavior in front of light radiations. Then, we made a comparison between the bios films having undergone the light stress and those which did not undergo any stress. This allowed us to observe that light and/or heat made our bio films more resistant. However, further studies are needed to improve the mechanical properties of these bio films. In particular, shooting with the scanning electron microscope, but above all making and comparing MIR spectra of the different varieties of biofilms obtained without forgetting the DSC to account for the new matrix formed within bioplastics.

\section{Acknowledgements}

I sincerely thank Professor Raymond. G. Elenga for his participation in the analysis and discussions on the stability of bioplastics although he is not a co-author. I would also like to thank the students Emmanuelle Ouanadio and Pascale Nkoua Ouassamo for giving time to the reproducibility of the different experiments. Without forgetting Professor Vincent Verney for his many contributions and advice.

\section{Conflicts of Interest}

The authors declare no conflicts of interest regarding the publication of this paper.

\section{References}

[1] Djetoui, Z. and Djerboua, F. (2012) Préparation d'un Polymère Thermoplastique Biodégradable à based'Amidon de Maïs. In 3 ème Conférence Internationale sur le Soudage, le CND et I Industrie des Matériaux et Alliages (IC-WNDT-MP12).

[2] Mufeng, L.N.D., Batiango, J.N., Ndongala, C.M. and Ndyanabo, J.T.M. (2020) Revue Africaine d'Environnement et d'Agriculture. Revue Africaine d'Environnement et d'Agriculture, 3, 121-128. 
[3] Vodouhe-Egueh, S., Alidou, C., Aboudou, K. and Soumanou, M.M. (2017) Formulation de biscuits à base de farine de blé enrichie à la farine de patate douce à chair orange. Afrique Science, 13, 405-416.

[4] Belili, C.P. (2015) THESE élaboration et caractérisation des biofilms, 75-82.

[5] Fouzia, J. (2011) THESE Elaboration de matériaux à base de farine de maïs: évaluation et compréhension des relations entre structure et cinétique de biodégradation, 50-80.

[6] Boula, E.F.M., Mananga, V., Elenga, M. and Kinkela, T. (2016) Étude des habitudes alimentaires des ménages de Brazzaville en vue de la lutte contre la carence en vitamine A. Journal of Applied Biosciences, 97, 9174-9186. https://doi.org/10.4314/jab.v97i1.4

[7] Tshizembe, D.M., Jadika, C.T., Ngeleka, T.T., Mbaji, A.K.N., Bongali, A.B. and Mutombo, S.B. (2018) valuation des clones de manioc pulpe jaune pour leur teneur en-carotne, rendements en tubercules frais et teneur en matire sche Ngandajika en Republique Democratique du Congo. Journal of Applied Biosciences, 124, 12497-12505. https://doi.org/10.4314/jab.v124i1.11

[8] Merchat, M. and Forêt, C. (2021). 9 Les biofilms dans les circuits de refroidissement industriels. In: Interactions Matériaux-Microorganismes, EDP Sciences, 189-214. https://doi.org/10.1051/978-2-7598-2112-9.c011

[9] Fouilloux, A. (2019) Formulations du glycérol pour P amélioration et Pélargissement des propriétés de fonction du film de caséinate de sodium (Doctoral dissertation, Lyon).

[10] Boumerdassi, K. (2016) Elaboration et Caractérisation de matériaux rigides à base d'amidon-g-bis acrylamide et renforts polysaccharides (Doctoral dissertation, Université M'hamed Bougara de Boumerdès, Département de Gén).

[11] Podshivalov, A., Besson, F., Budtova, T. and Bronnikov, S. (2018) Morphology and Improved Impact Strength of Cellulose Acetate Butyrate Blended with Polyethylene Copolymer. Express Polymer Letters, 12, 856-866. https://doi.org/10.3144/expresspolymlett.2018.74

[12] Hammache, Y., Serier, A. and Chaoui, S. (2020) The Effect of Thermoplastic Starch on the Properties of Polypropylene/High Density Polyethylene Blend Reinforced by Nano-Clay. Materials Research Express, 7, Article ID: 025308. https://doi.org/10.1088/2053-1591/ab7270

[13] Rivadeneira-Velasco, K.E., Utreras-Silva, C.A., Díaz-Barrios, A., Sommer-Márquez, A.E., Tafur, J.P. and Michell, R.M. (2021) Green Nanocomposites Based on Thermoplastic Starch: A Review. Polymers, 13, 3227.

https://doi.org/10.3390/polym13193227

[14] Dutta, N., Hazarika, S. and Maji, T.K. (2021) Study on the Role of Tannic Acid-Calcium Oxide Adduct as a Green Heat Stabilizer as Well as Reinforcing Filler in the Bio-Based Hybrid Polyvinyl Chloride-Thermoplastic Starch Polymer Composite. Polymer Engineering \& Science, 61, 2339-2348. https://doi.org/10.1002/pen.25761

[15] Praud, R. (2021) La photoprotection, de la photosensibilité à la phototoxicité. Revue Francophone d'Orthoptie. https://doi.org/10.1016/j.rfo.2020.10.001 